\title{
Social housing influences the behavior and feed intake of dairy calves during weaning
}

\author{
M. A. Overvest, ${ }^{*}$ R. E. Crossley, ${ }^{*}$ E. K. Miller-Cushon, $\dagger$ and T. J. DeVries ${ }^{* 1}$ \\ *Department of Animal Biosciences, University of Guelph, Guelph, ON, N1G 2W1, Canada \\ †Department of Animal Sciences, University of Florida, Gainesville 32611
}

\begin{abstract}
We investigated the effect of social housing on the behavioral, intake, and physiological changes that occur at weaning for dairy calves fed milk ad libitum. These changes were evaluated during the weaning (d 40 to 48 of age) and postweaning (d 49 to 56 of age) stages. Twenty male Holstein calves were fed milk replacer ad libitum and weaned gradually by dilution over $9 \mathrm{~d}$ starting at d 40 of age. Calves were housed in pairs (10 calves) or individually (10 calves) from birth until the beginning of the postweaning phase, when all calves were paired. Feed and water intake were monitored daily. Feeding time was video-recorded, and blood $\beta$-hydroxybutyrate concentration was measured on alternate days beginning on d 40 and ending on d 56 of age. Electronic accelerometers continuously recorded standing and lying behavior for the 17-d study. Solid feed consumption increased by more than 5 -fold over the weaning phase in all calves; during this phase pairhoused calves consumed more than twice ( 0.96 vs. 0.50 $\mathrm{kg} / \mathrm{d}$ on $\mathrm{d} \mathrm{48)}$ that of the individually housed calves. Postweaning all calves rapidly increased their solid feed intake, and to a greater extent for previously individually housed calves, such that intake was similar between treatments by d 56 . Free water intake was stable during weaning; however, a decrease (of $6.6 \mathrm{~L}$ ) occurred in the constituent milk replacer water intake across this phase. As result, total water intake (free water + milk replacer water content) decreased (by $6.0 \mathrm{~L}$ ) over the weaning phase between d $40(14.9 \mathrm{~L} / \mathrm{d})$ and d $48(8.9$ $\mathrm{L} / \mathrm{d}$ ). On the first day postweaning (d 49), total water intake for all calves increased sharply (to $19.0 \mathrm{~L} / \mathrm{d}$ ) and then returned to a lower baseline $(13.2 \mathrm{~L} / \mathrm{d})$ the next day (d 50), and slowly increased over the following week. During the weaning phase, feeding time and feeding rate increased with time for all calves, whereas pair-housed calves had greater feeding rates than in-
\end{abstract}

Received January 17, 2018.

Accepted May 14, 2018.

${ }^{1}$ Corresponding author: tdevries@uoguelph.ca dividually housed calves (13.4 vs. $6.6 \mathrm{~g}$ of $\mathrm{DM} / \mathrm{min}$ ). After weaning, calves previously housed individually spent more time feeding in the early hours of the day than calves housed in pairs. Lying time and lying bout frequency decreased with calf age during the weaning period across treatments, and pair-housed calves tended to spend less time lying than individually housed calves (1,015 vs. $1,039 \mathrm{~min} / \mathrm{d})$ during this time period. Blood $\beta$-hydroxybutyrate increased across treatments over the weaning period, with the largest increase occurring between d $48(0.05 \mathrm{mmol} / \mathrm{L})$ and $\mathrm{d} 50(0.2 \mathrm{mmol} / \mathrm{L})$. These results show that calves alter their behavioral patterns during weaning and that housing calves in pairs may ease the transition from milk to solid feed.

Key words: dairy calf, behavioral pattern, weaning

\section{INTRODUCTION}

Increasing milk allowance improves the well-being of young dairy calves by decreasing behavioral signs of hunger (De Paula Vieira et al., 2008), encouraging natural feeding patterns (Appleby et al., 2001), and increasing growth rates (Jasper and Weary, 2002; Miller-Cushon et al., 2013a; Rosenberger et al., 2017). Increased growth rates in early life, through higher milk allowance and other management strategies, may also improve long-term performance when the calf enters the milking herd (Soberon et al., 2012; Soberon and Van Amburgh, 2013; Gelsinger et al., 2016). However, providing greater quantities of milk creates a challenge at weaning because calves consume less solid feed before weaning when provided with more milk (Terré et al., 2007; Miller-Cushon et al., 2013a) and may have reduced weight gain during the weaning transition (Sweeney et al., 2010). Improvements to current weaning programs may help eliminate these setbacks. For example, increasing the duration of the weaning period (Sweeney et al., 2010), utilizing different methods of weaning (e.g., step down weaning; Khan et al., 2007), offering different types of solid feeds, such as forages (Castells et al., 2012), or providing access to herdmates (Chua et al., 2002; Costa et al., 2016; Bolt et al., 
2017) may improve the transition to solid feed over the weaning period.

Evidence indicates that social housing improves feed intake during the weaning period (De Paula Vieira et al., 2010; Miller-Cushon and DeVries, 2016); these data suggest that social facilitation or social learning of feeding may benefit calf intake and, thus, growth preweaning, during weaning, and postweaning (Costa et al., 2016). Effects of early social housing and early exposure to competition may have longer-term effects on calves, as there is evidence that calves previously housed in groups have greater competitive success immediately after weaning (Duve et al., 2012) and calves exposed to early competition exhibit increased competitive behavior for access to feed 6 wk after weaning (Miller-Cushon et al., 2014). Early social housing may also influence behavioral (Duve et al., 2012) and cognitive development (Gaillard et al., 2014; Meagher et al., 2015), and improve resilience to stress (Bolt et al., 2017) and competitive interactions (Miller-Cushon et al., 2014) postweaning.

Despite the importance of facilitating a smooth transition at weaning, especially in calves provided greater milk allowances, the day-to-day behavioral, intake, and physiological changes that occur during the weaning process have not been well characterized. The primary objective of this study was to investigate the behavioral and intake changes that occur during weaning for dairy calves fed milk ad libitum. Further, due to the influences of social housing on intake before and during weaning (De Paula Vieira et al., 2010; Miller-Cushon and DeVries, 2016), we also aimed to determine the effect of social housing on behavioral and intake changes that occur at weaning. We predicted that calves raised individually would show less synchronicity in their feeding behavior after being paired following weaning. During times of stress (i.e., social mixing) cows have been reported to decrease lying time temporarily (von Keyserlingk et al., 2008), thus it was hypothesized that calves would alter their normal lying behavior by standing for longer periods of time per day during a high-stress period such as weaning.

As reviewed by Khan et al. (2016), ruminal fermentation begins early in life, and VFA concentrations increase with greater solid feed intake. Butyrate, the most bioactive VFA, is absorbed by the rumen epithelium and oxidized into ketones (Baldwin et al., 2004; Khan et al., 2016). One of these ketones, BHB, is expected to increase with calf age due to higher feed intakes and absorption of short-chain fatty acids from the rumen (Swanson and Harris, 1958; Quigley et al., 1991, 1992; Deelen et al., 2016). Although researchers have positively associated blood BHB with starter intake in early life of the calf, with weekly samples (Deelen et al.,
2016; Suarez-Mena et al., 2017), a comprehensive study of how blood BHB evolves over the weaning period with increasing starter consumption has not been done. Thus, another aim of this study was to investigate how blood BHB changes over the weaning period.

\section{MATERIALS AND METHODS}

This study was part of a larger study aimed at evaluating how social housing affects development of feeding behavior and social feeding habits of dairy calves. As such, detailed descriptions of the methodology of the study are presented in Miller-Cushon and DeVries (2016). To address the current objectives, this study focused on the time period around weaning (9 d of weaning, and the following $8 \mathrm{~d}$ postweaning), and investigated daily changes in behavior across this period.

\section{Animals and Housing}

Twenty male Holstein calves were used in this study. Calves were purchased from local dairy farms (Eastern Ontario, Canada) and transported to the University of Guelph Kemptville Campus Dairy Education and Research Centre (Kemptville, ON, Canada). Prior to transport, it was confirmed that calves received a minimum of 1 feeding of colostrum (minimum $4 \mathrm{~L}$ within the first $12 \mathrm{~h}$ of life) and were tagged with a National Livestock Identification for Dairy tag before removal from the farm. Calves were assessed by study technicians at the farm of origin and only calves deemed healthy and alert were purchased. All calves arrived at the research facility within $24 \mathrm{~h}$ of birth. On arrival and enrollment in the study, calves received injections of $1 \mathrm{~mL}$ of selenium (Dystosel, Pfizer Animal Health, Kirkland, QC, Canada) and $1 \mathrm{~mL}$ of tulathromycin (Draxxin, Pfizer Animal Health), as a preventive measure to reduce incidence of illness (Stanton et al., 2013). Body weight of calves on arrival was $43.3 \pm 5.5 \mathrm{~kg}$. At the research farm, calves were managed under the standard operating procedures of the research center, in accordance with the guidelines set by the Canadian Council on Animal Care (CCAC, 2009) and as approved by the University of Guelph Animal Care Committee (AUP\# 1913). The day of arrival at the research farm marked d 0 of the study. Each new day of the trial began when fresh milk was delivered (0900 h).

Calves were randomly assigned to a treatment group upon arrival at the research farm: 10 calves were housed in pairs, whereas the other 10 calves were housed individually until after milk weaning (d 50), at which time they were switched to pair housing. Calves in each pair arrived at the farm on the same day and were paired, at random (if more than 2 calves arrived at the same 
time), immediately upon arrival. The research facility consisted of a covered structure with 1 open side to provide air circulation while protecting calves from the elements. Calf pens were located along the rear wall of the building. Pens that housed paired calves $(\mathrm{n}=5,10$ calves; $2.4 \times 1.8 \mathrm{~m}$; width $\times$ depth) were alternated with 2 pens that contained individually housed calves $(\mathrm{n}=10 ; 1.2 \times 1.8 \mathrm{~m})$. Postweaning (d 50 of age), calves reared individually were paired within treatment, by removing the wall between adjacent individually housed pens. All pens had 3 solid sides (1.3 m high) and a metal gate at the front fitted with 2 openings on each gate that allowed calves access to feed buckets mounted below. Pre-weaning, each calf had access to two 8-L capacity pails, one containing solid feed and one containing fresh water. Postweaning, these buckets were exchanged for larger pails $(20 \mathrm{~L})$ containing the postweaning solid feed and fresh water. Pens were bedded with wood shavings that were replenished as needed and fully replaced at least twice per week.

To ensure that the number of experimental units (pens) per treatment was adequate to detect statistical differences in treatment response, a power analysis (Morris, 1999; Hintze, 2008) was performed before the study for the primary response variables, including feeding (intake and time) and lying behavior. Estimates of variation for these variables (mean $\mathrm{CV}=16 \%$ ) were based on previously reported values (Miller-Cushon et al., 2013b,c, 2014; Overvest et al., 2016). From the power analysis, it was determined that at $80 \%$ power, treatment differences of $\sim 20 \%$ could be detected at this sample size ( $\mathrm{n}=5$ pens per treatment).

\section{Feeding Management}

Prior to weaning, all calves had ad libitum access to milk replacer, mixed as directed at $150 \mathrm{~g} / \mathrm{L}$ (Optivia Advantage Milk Replacer, Nutreco Canada Inc., Guelph, Canada; $26 \%$ CP, $16 \%$ fat). Milk replacer was mixed fresh every morning and the desired $\mathrm{pH}$ of the milk replacer (4.0 to 4.5) was achieved by adding a prediluted $9.8 \%$ formic acid solution (The Acidified Milk Solution, NOD Apiary Products Ltd., Frankford, Canada) to prevent microbial growth. An artificial teat (Peach Teats, Skellerup Industries Ltd., Woolston, New Zealand) was mounted to the gate of each pen with a milk tube fitted with a 1-way valve running into a covered bucket placed outside of the pen. In the case of the paired calves, 2 teats were mounted side by side (to ensure each calf could access milk ad libitum) and each hose led into the same bucket on the outside of the pen. Because calves were fed ad libitum, milk-feeding apparatus were removed at $0800 \mathrm{~h}$ to be cleaned and orts weighed back before fresh milk replacer was offered at $0900 \mathrm{~h}$ each morning. Milk replacer was replenished and stirred as needed at $1600 \mathrm{~h}$ to ensure continual access. Prior to weaning, calves were also offered ad libitum access to a textured dairy starter concentrate [Rooney's Feeds, Iroquois, ON, Canada; containing $36.5 \%$ corn, $28 \%$ calf starter supplement (Shur-Gain, Nutreco Canada Inc., Guelph, ON, Canada), $20 \%$ rolled barley, $2.5 \%$ dilute monensin sodium, $2 \%$ molasses, and $1 \%$ soybean oil], as described in Miller-Cushon and DeVries (2016).

Milk weaning by dilution (following Nielsen et al., 2008) began at d 40 and was complete by d 49 . When implementing milk weaning by volume reduction, one pair-housed calf may consume a larger volume of milk, leaving the other calf less milk. Because half of the calves were pair housed at this time, milk replacer was diluted on d 40,43, 46, and 49 by $25,50,75$, and $100 \%$, respectively, to reduce the risk of large variation in intake between pair-housed calves. During weaning, a pelleted feed (Shur-Gain High Fiber Dairy Heifer Ration, 20\% protein, Shur-Gain Nutreco Canada Inc.), as described in Miller-Cushon and DeVries (2016), was mixed at a rate of 50:50 with the pre-weaning starter feed to ease the transition to the new diet. Postweaning, calves were provided, ad libitum, solely this pelleted diet. Fresh solid feed was offered at 1000 h daily throughout the study. On d 49, calves were completely weaned and offered only water on this day through the milk feeding apparatus, thus beginning the postweaning period. On d 50 the milk feeding system was fully removed from each pen.

\section{Calf Behavior and Physiological Measures}

Daily intakes of concentrate, milk replacer, and water were recorded at the pen level. Intakes were calculated based on weight offered and the quantity refused at the start of the following day. To ensure ad libitum access to solid feed, an orts level of $>15 \%$ was maintained. Fresh and orts samples were taken weekly (1 fresh, 1 orts/pen) to determine accurate DMI. All samples were frozen at $-20^{\circ} \mathrm{C}$ until time of analysis. Samples were then thawed and dried in an oven at $55^{\circ} \mathrm{C}$ for $48 \mathrm{~h}$ to determine DM content of the feed.

Calves were fitted with accelerometers (HOBO Pendant G Data Logger, Onset, Pocasset, MA) to assess standing and lying behavior over the weaning period (as validated for use in calves by Bonk et al., 2013). Accelerometers were secured onto the rear leg of each calf with veterinary bandaging tape (Vetrap Bandaging Tape, 3M, London, ON, Canada), as per the UBC AWP (2013), on d 33 of life. Accelerometers were removed and promptly replaced on d 41, and again on d 49, to ensure continuous data collection. At each change, the 
new accelerometers were secured to the opposite rear leg. The devices were removed on d 57. Data were collected from the accelerometers for standing and lying times, as well as length and frequency of all lying bouts.

Six color video cameras (day/night camera, model no. WV-CP504, Panasonic, Osaka, Japan) with F0.95/2.8 to $8 \mathrm{~mm}$ lenses (Fujinon CCTV lens, Fuji, Tokyo, Japan) recorded continuously at 15 images/s for the duration of the study. A digital video recorder (digital disk recorder, model no. WJ-HD616K, Panasonic) received video feed from these cameras and allowed viewing of the video footage for analysis. Cameras were mounted $4 \mathrm{~m}$ from the barn floor and $2 \mathrm{~m}$ from the front edge of calf pens. The front of each pen was clearly visible on at least one camera to allow a clear view of feed buckets and milk feeding apparatuses. To obtain clear nighttime recordings, 5 red lights $(100 \mathrm{~W})$ were spaced evenly between cameras and set to turn on at nightfall. Feeding time was observed on alternate days beginning on d 40 and ending on d 56; for all $9 \mathrm{~d}$ of behavioral recording, video data were analyzed using instantaneous scans at 1-min intervals for milk-feeding and solid feed consumption (as validated by Miller-Cushon and DeVries, 2011). Milk-feeding was noted if a calf had its mouth closed on the teat and with milk flow through the hose. Solid feed consumption was recorded if the calf's head was lowered into the feed pail. To calculate feeding rate, total daily feeding time was divided by total solid feed (on a DM basis), in grams, consumed that day.

To determine blood BHB concentration throughout the trial, as a proxy for rumen physiological development (Deelen et al., 2016), a Precision Xtra meter (Abbott Diabetes Care, Saint Laurent, Canada; validated in cows by Iwersen et al., 2009) was used with blood ketone test strips (Abbott Diabetes Care). This test was performed at $1300 \mathrm{~h}$, for a total of 9 collection days, on days corresponding to the video observation of feeding behavior. During sampling, calves were restrained by placing them in a halter, tying off the halter to the pen gate, and pressing their body between the pen wall and the person sampling. During each test, a very small amount of blood $(<1 \mathrm{~mL})$ was drawn from the coccygeal vein using a 23-gauge needle and $1-\mathrm{mL}$ syringe. A droplet of blood was then placed on the test strip and the reader indicated results of blood BHB concentration in millimoles per liter.

\section{Statistical Analysis}

For both individually housed and pair-housed calves, data were summarized at a pen (pair) level. When data were collected for individual calves, it was averaged across pen (i.e., for individually housed calves before weaning), data were averaged across adjacent calves. Data were averaged across calves in the pen to yield averages, expressed on a per calf basis, for analysis.

Prior to analysis, data were screened for normality using the UNIVARIATE procedure of SAS (2012, version 9.4, SAS Institute Inc., Cary, NC). All values reported are least squares means. Significance was declared at $P \leq 0.05$, and tendencies were reported if 0.05 $\leq P \leq 0.10$.

All data collected were summarized and analyzed by period: weaning (d 40-48) and postweaning (d 49-56). Data were analyzed using the MIXED procedure of SAS, treating day as a repeated measure. The model included the fixed effects of treatment (individual or pair-housed), day, and treatment $\times$ day interaction. To account for the repeated measures within subject (experimental unit), variance-covariance matrix structures were chosen for each variable on the basis of best fit according to Schwarz's Bayesian information criterion. Heterogeneous autoregressive was selected as the correlation structure for milk volume and milk replacer water intake, whereas autoregressive was selected for free water intake, total water intake (postweaning), lying bout frequency, and BHB. Compound symmetry was selected for total water intake (weaning) and lying time. Variance components was selected for milk replacer DMI, solid DMI (weaning), and total DMI, and Toeplitz was selected for solid DMI (postweaning). Multiple comparisons were analyzed for variables subject to a treatment by day interaction using the Tukey-Kramer adjustment.

To investigate the effect of social housing on the within-day patterns and synchronicity of feeding behavior of calves over the weaning period, an analysis of diurnal patterns of feeding was performed on milk feeding time for the weaning phase, as well as on solid feeding time for both periods. Time spent performing these behaviors were summed by hour and averaged by pen (expressed on a per calf basis) and hour across all recording days in each period. Data were analyzed using the MIXED procedure of SAS, treating hour as a repeated measure. The model included treatment, hour, and treatment $\times$ hour interaction as fixed effects. To account for the repeated measures within subject, an autoregressive variance-covariance matrix structure was chosen on the basis of best fit according to Schwarz's Bayesian information criterion.

One calf in the pair housed system did not thrive (with extremely low intakes of milk and solid feed, and resultant poor growth), before and during the weaning period, and was later euthanized. Data from this calf, during the weaning period, were classified as an outlier after using the DFFIT procedure of SAS (with a cut-off value of \pm 2 ) to determine if these data imposed a bias 


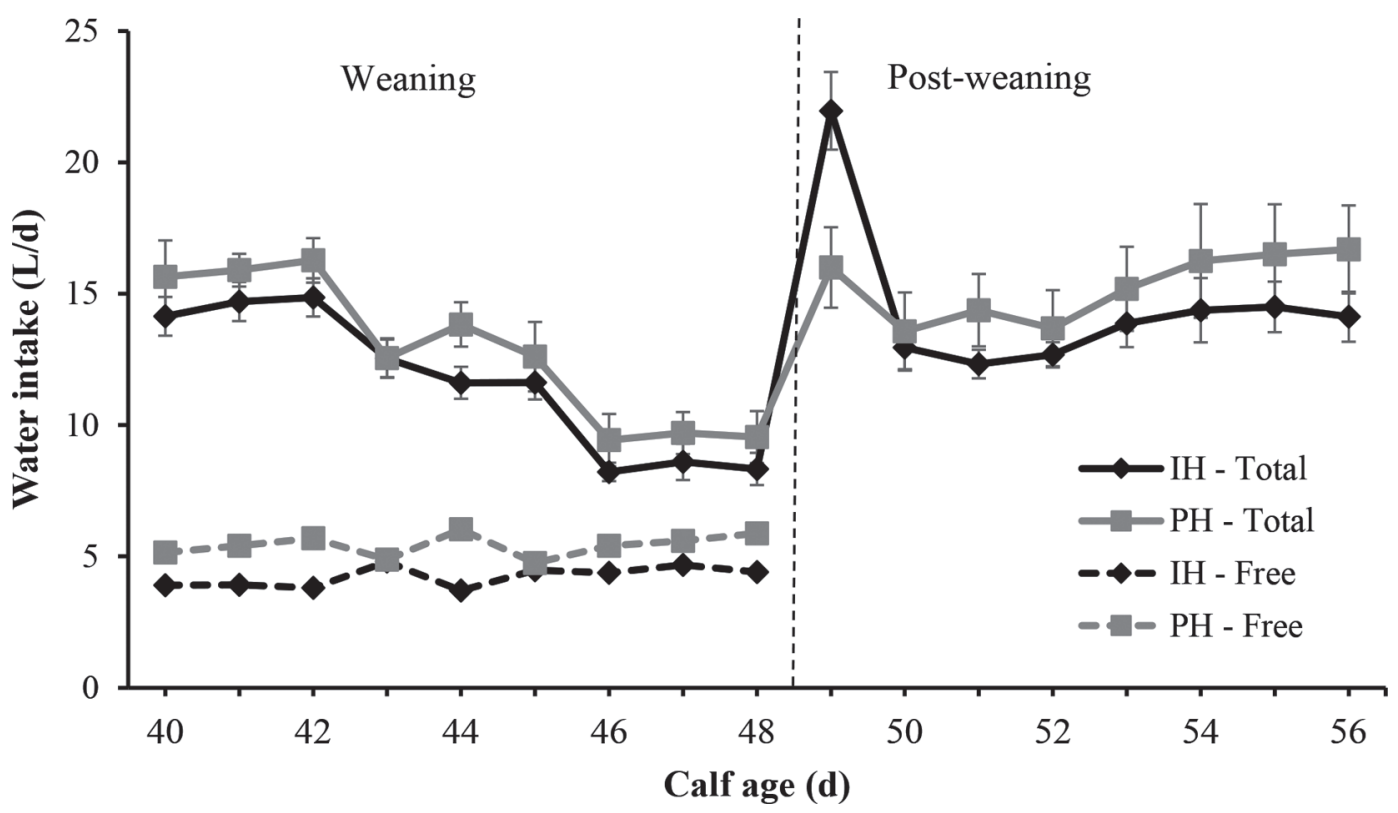

Figure 1. Daily water intake $( \pm \mathrm{SE})$ for the weaning and postweaning periods. During weaning, the total water (solid line) consumed consisted of both free water (dashed line) and that from milk replacer. Values are shown separately for calves housed in individual pens for the weaning stage, then pair-housed postweaning (IH), and calves housed in pairs for the entire trial (PH).

on the described statistical models; thus the data from both calves in this pair were removed from all analyses.

\section{RESULTS}

During the weaning phase (d 40-48), social housing had no effect on milk feeding time. Calves spent approximately $43.6 \pm 6.44 \mathrm{~min} / \mathrm{d}$ drinking milk and a tendency $(P=0.09)$ was observed for this time to increase with age over the weaning period. Weaning by diluting the milk ration meant that the total volume of milk offered (milk replacer + water) did not change over the weaning period, yet the total volume of milk consumed decreased across the days for all calves, with an average change in intake of $7.1 \mathrm{~L}(P<0.001)$, corresponding to a reduction in milk replacer DMI of $1.5 \mathrm{~kg}(P<0.001)$. No effect was observed of housing treatment on volume of diluted milk consumed (individually housed $=7.65 \pm 0.36 \mathrm{~L} / \mathrm{d}$ vs. pair-housed $=$ $7.66 \pm 0.41 \mathrm{~L} / \mathrm{d}, P=0.99)$ or milk replacer DMI during weaning (individually housed $=0.74 \pm 0.02 \mathrm{~kg} / \mathrm{d}$ vs. pair-housed $=0.74 \pm 0.02 \mathrm{~kg} / \mathrm{d}, P=0.98)$.

Although it did not differ between treatments, total water intake (free water + milk replacer water content) decreased over the weaning period with an average change in intake of $6.0 \mathrm{~L}$ between $\mathrm{d} 40$ and $\mathrm{d} 48(P<$ 0.001; Figure 1). No effect was observed of day on the free water intake during the weaning stage; however, a decrease occurred in the constituent milk replacer water intake, with an average decrease of $6.6 \mathrm{~L}$ across the period $(P<0.001)$. On the first day postweaning (d 49), total water intake for both groups increased sharply, and then returned to a lower baseline and slowly increased over the following week $(P<0.001)$. Water intake during this week was subject to a treatment by day interaction $(P=0.006)$, with pair-housed calves exhibiting more stable water intake, whereas individually housed calves had a numerically greater spike in water intake immediately postweaning (22.0 vs $16.0 \mathrm{~L} / \mathrm{d} ; \mathrm{SE}=1.93 ; P=0.17)$ and then dropped to a lower baseline.

Milk feeding rate during weaning was subject to a treatment by day interaction $(P<0.05)$, with individually housed calves consuming milk more rapidly than pair-housed calves on the first day of weaning (45.8 vs $36.5 \mathrm{~g} / \mathrm{min} ; P=0.03)$. Diurnal feeding patterns for milk intake during the weaning period (Figure 2a) show that milk feeding time varied throughout the day, with no effect of treatment, with peaks around 0900, 1300, and $1900 \mathrm{~h}$.

All calves increased their solid feed intake rapidly over the weaning period $(P<0.001$; Figure 3$)$. During this time, pair-housed calves consumed more than the twice the amount of solid feed as individually housed calves $(P<0.001)$. Across treatments, time spent consuming solid feed $(P<0.001 ;$ Figure 4$)$ and the feeding rate of solid feed $(P<0.001)$ increased over time before weaning. Calves on the pair-housed treatment had a greater feeding rate than individually housed calves during this period (13.4 vs. $6.6 \mathrm{~g}$ of $\mathrm{DM} / \mathrm{min} ; \mathrm{SE}=2.16 ; P=0.01$ ). 
Diurnal patterns of solid feed consumption were similar $(P=0.95)$ during the weaning period (Figure $2 \mathrm{~b})$ for both treatment groups, showing peaks in feeding time around 0900, 1300, and $1900 \mathrm{~h}$.

In the postweaning stage, feed intake continued to increase with age for all calves $(P<0.001$; Figure 3$)$. An interaction of treatment and day was detected, with individually housed increasing their solid feed DMI to a greater extent over time than pair-housed calves $(P=$ $0.05)$, such that intake was similar between treatments by d 56 (Figure 3). The individually housed calves also tended to spend more time feeding than pair-housed (132.5 vs. $103.5 \mathrm{~min} / \mathrm{d} ; \mathrm{SE}=17.49 ; P=0.06$; Figure 4). During this time, feeding rate increased with calf age $(P<0.001)$ but was similar between treatments $(15.9 \pm 2.87 \mathrm{~g} / \mathrm{min} ; P=0.11)$. Postweaning diurnal patterns of solid feeding time differed by treatment $(P$ $=0.01$; Figure 5 ). Calves previously housed individually in single pens spent more time feeding in the early hours of the day than calves housed in pairs.

During weaning, lying time (Figure 6) was subject to a treatment by day interaction $(P=0.02)$, tended to be lower overall for pair-housed calves $(P=0.06)$, and decreased with age for all calves $(P<0.001)$. In the postweaning period, lying time was again subject to a treatment by day interaction $(P<0.001$; Figure 6$)$ with newly paired individually housed calves decreasing lying time on d 50 when they were first paired, compared with previously pair-housed calves $(P=0.04)$. All calves also tended to increase their lying time with age in the postweaning stage $(P=0.07)$. Lying bout frequency decreased by day during the weaning period $(P<0.001)$, but did not change with calf age postweaning $(P=0.96)$. There was no effect of treatment on lying bout frequency at any time point (Figure 7).

No treatment differences were observed in blood BHB concentrations for the entire duration of the trial. During the weaning period, BHB increased with calf age $(P=0.01 ;$ Figure 8$)$. The most notable change in BHB occurred between d 48 and 50, immediately postweaning when BHB increased substantially. After that point, $\mathrm{BHB}$ remained stable for the remainder of the postweaning observation period.

\section{DISCUSSION}

Despite the importance of supporting feed intake and growth during the weaning period, little research to date has described the behavioral changes of dairy calves during the weaning period. The goal of the pres-

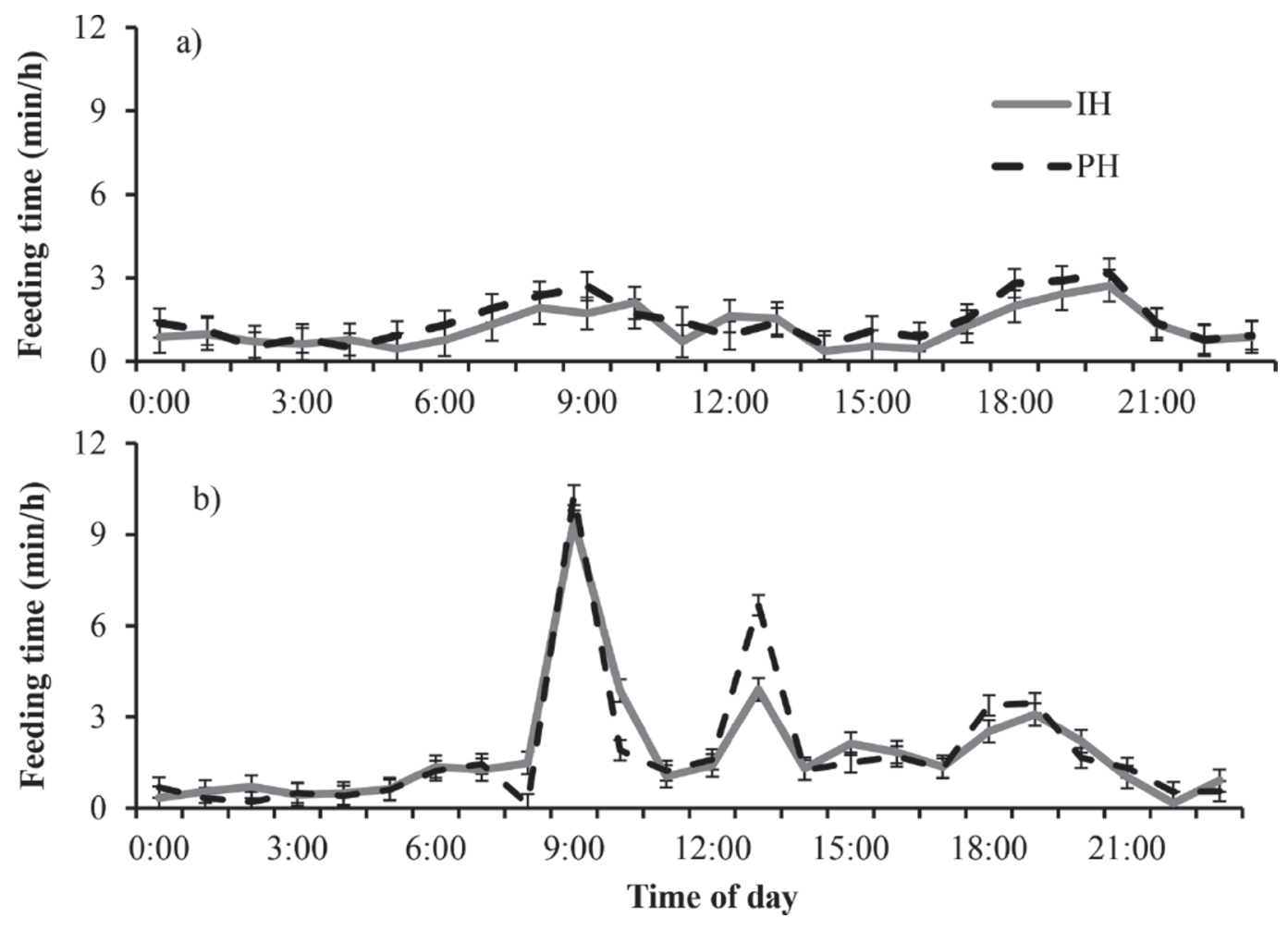

Figure 2. Diurnal feeding patterns (mean $\pm \mathrm{SE}$ ) of milk feeding (a) and solid feeding (b) for calves during the weaning period (d 40-48). Values are shown separately for calves housed in individual pens for the weaning stage, then pair-housed postweaning (IH), and calves housed in pairs for the entire trial $(\mathrm{PH})$. 


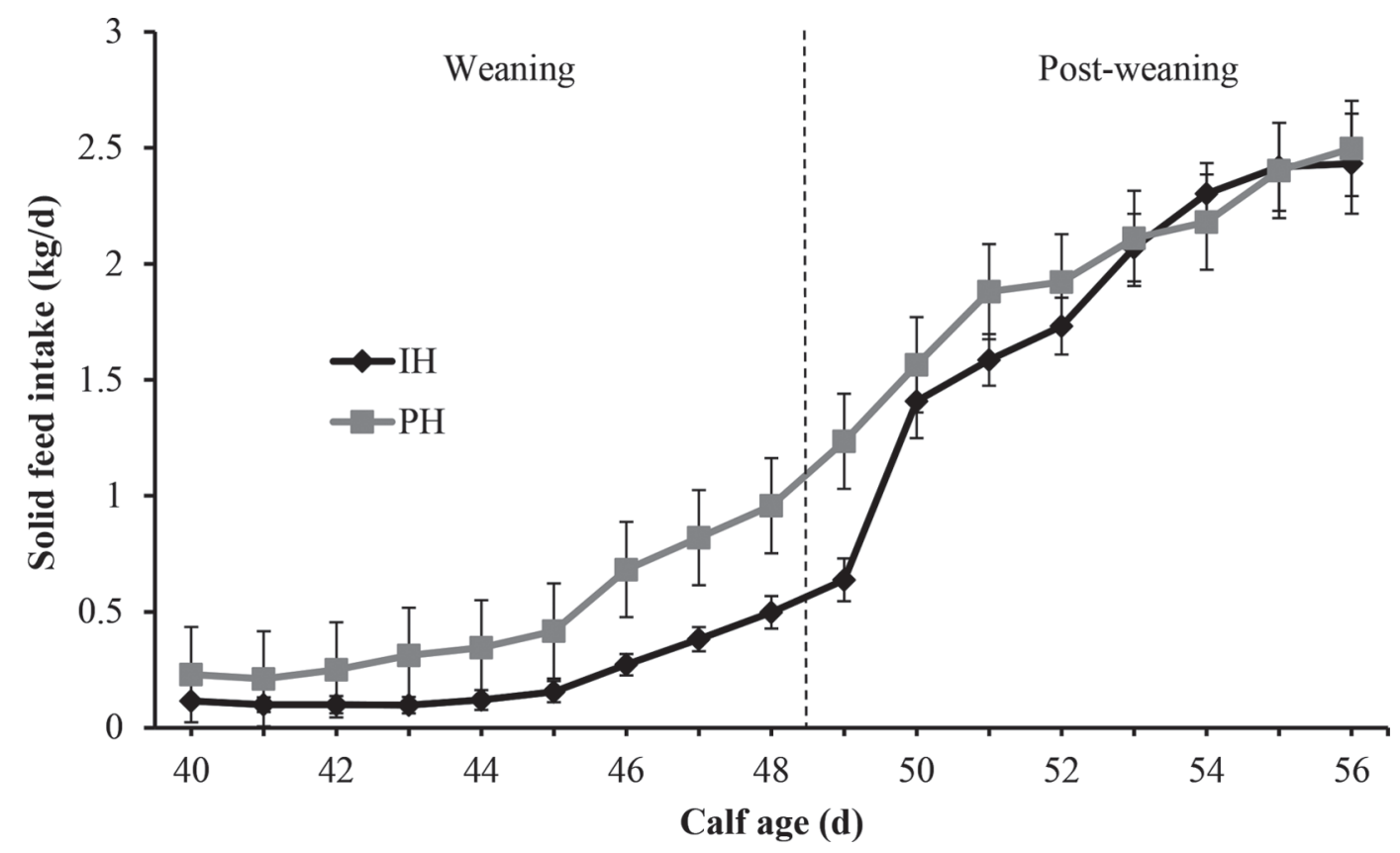

Figure 3. Mean $( \pm \mathrm{SE})$ daily solid feed intake $(\mathrm{DM})$. Values are shown separately for calves housed in individual pens for the weaning stage, then pair-housed postweaning $(\mathrm{IH})$, and calves housed in pairs for the entire trial $(\mathrm{PH})$.

ent study was to determine the effects of weaning calves from a high level of milk on behavioral, intake, and physiological changes that occur at weaning, as well as the effect of social housing at this time. Results suggest that both individually housed and pair-housed calves experienced behavioral changes around weaning time, including increasing feeding time, solid feed intake, and decreasing lying time and bout frequency.

Although all calves consumed low levels of solid feed during the milk-feeding stage, solid feed DMI increased

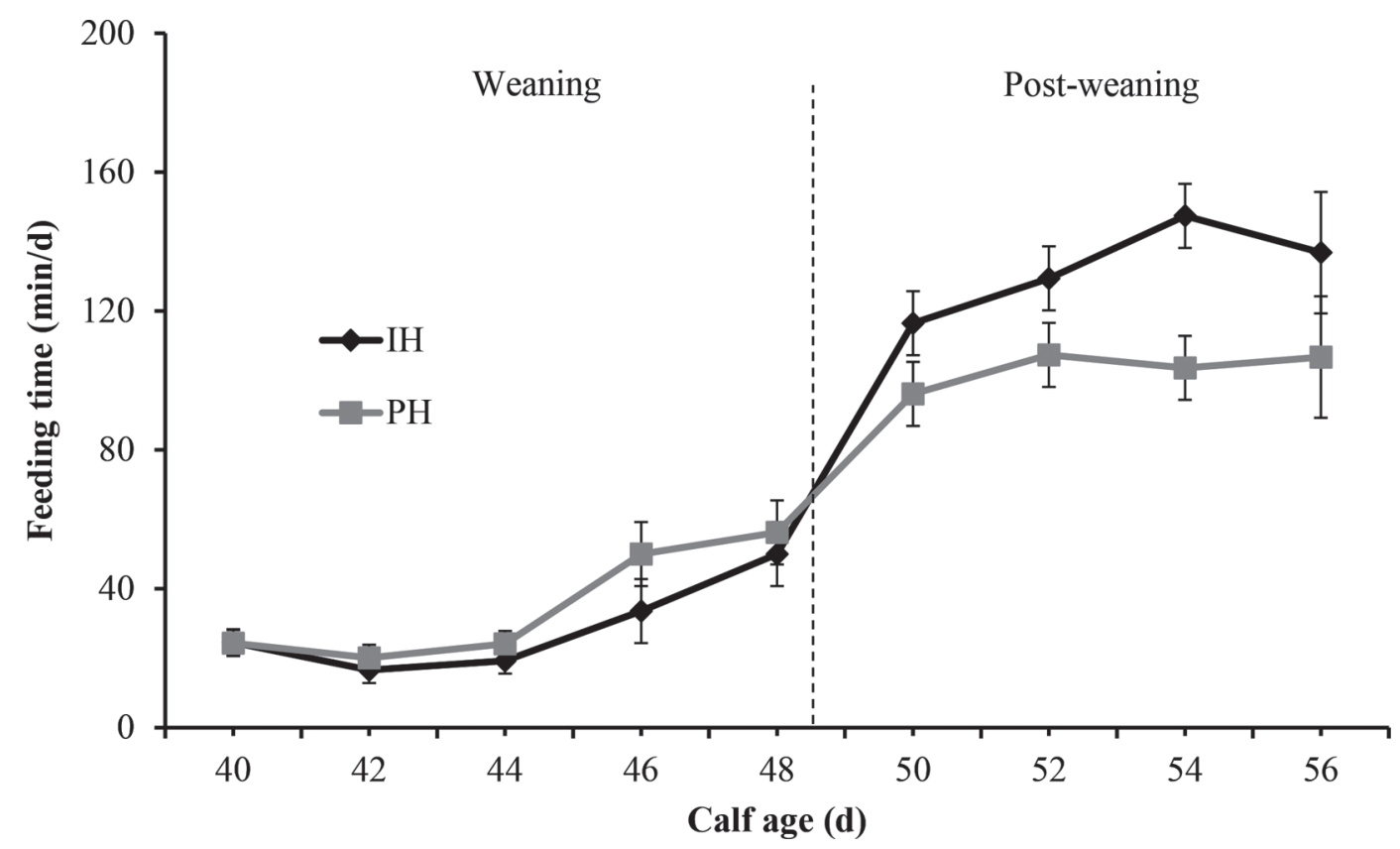

Figure 4. Mean $( \pm \mathrm{SE})$ daily solid feeding time. Values are shown separately for calves housed in individual pens for the weaning stage, then pair-housed postweaning $(\mathrm{IH})$, and calves housed in pairs for the entire trial $(\mathrm{PH})$. 


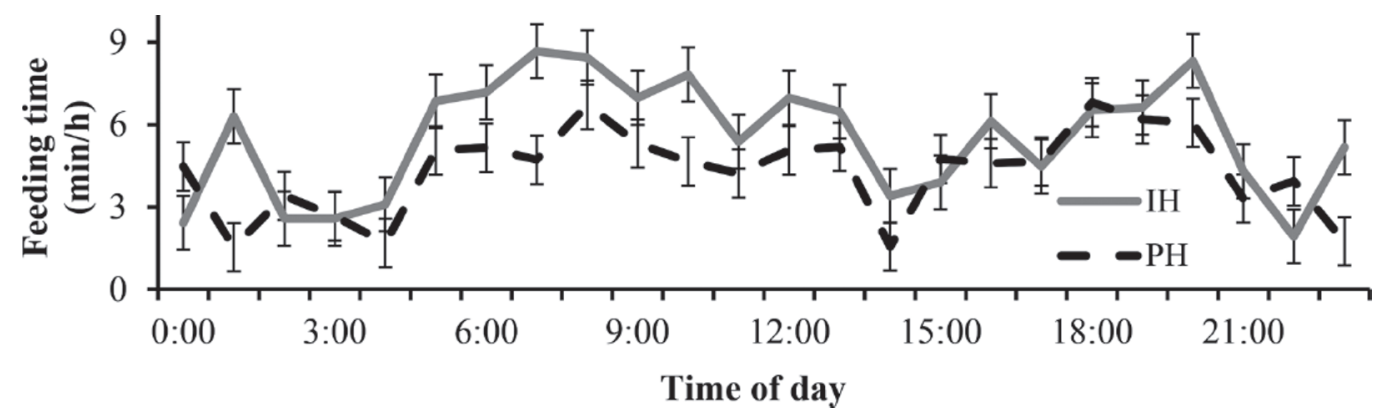

Figure 5. Diurnal feeding patterns (mean \pm SE) for calves during the postweaning period (d 49-56). Values are shown separately for calves housed in individual pens for the weaning stage, then pair-housed postweaning ( $\mathrm{IH})$, and calves housed in pairs for the entire trial (PH).

with calf age. Calves housed in pairs consumed more solid feed during the weaning period, likely due to social facilitation (De Paula Vieira et al., 2010; Jensen et al., 2015), as discussed further by Costa et al. (2016) and Miller-Cushon and DeVries (2016). Costa et al. (2014) recently reported that food neophobia was decreased in calves housed in complex social groups. Similar results also indicated that calves housed in groups show more behavioral flexibility and a higher degree of ease to adapt to novel stimuli (De Paula Vieira et al., 2012). Positive effects of social housing on food acceptance and behavioral flexibility may improve ability to cope with the stress of weaning transition. This is supported by work by Bolt et al. (2017), who demonstrated the stress buffering benefits that early social housing provides.
The increase in solid feeding time and solid feeding rate during the weaning phase aligns with the increase in feed intake and decreasing concentration of milk replacer available to the calves at that time. These results are consistent with other studies where calves have been weaned off ad libitum milk allowance (Chua et al., 2002; Jasper and Weary, 2002; Miller-Cushon et al., 2014). Calves on the pair-housed treatment consumed more solid feed and tended to spend more time feeding at a faster rate during the weaning phase, possibly due to the social learning influences of social housing (Costa et al., 2015; Jensen et al., 2015).

Postweaning, DMI continued to increase with calf age similarly between treatments. During the first $8 \mathrm{~d}$ postweaning, calves avoided altering their within-day

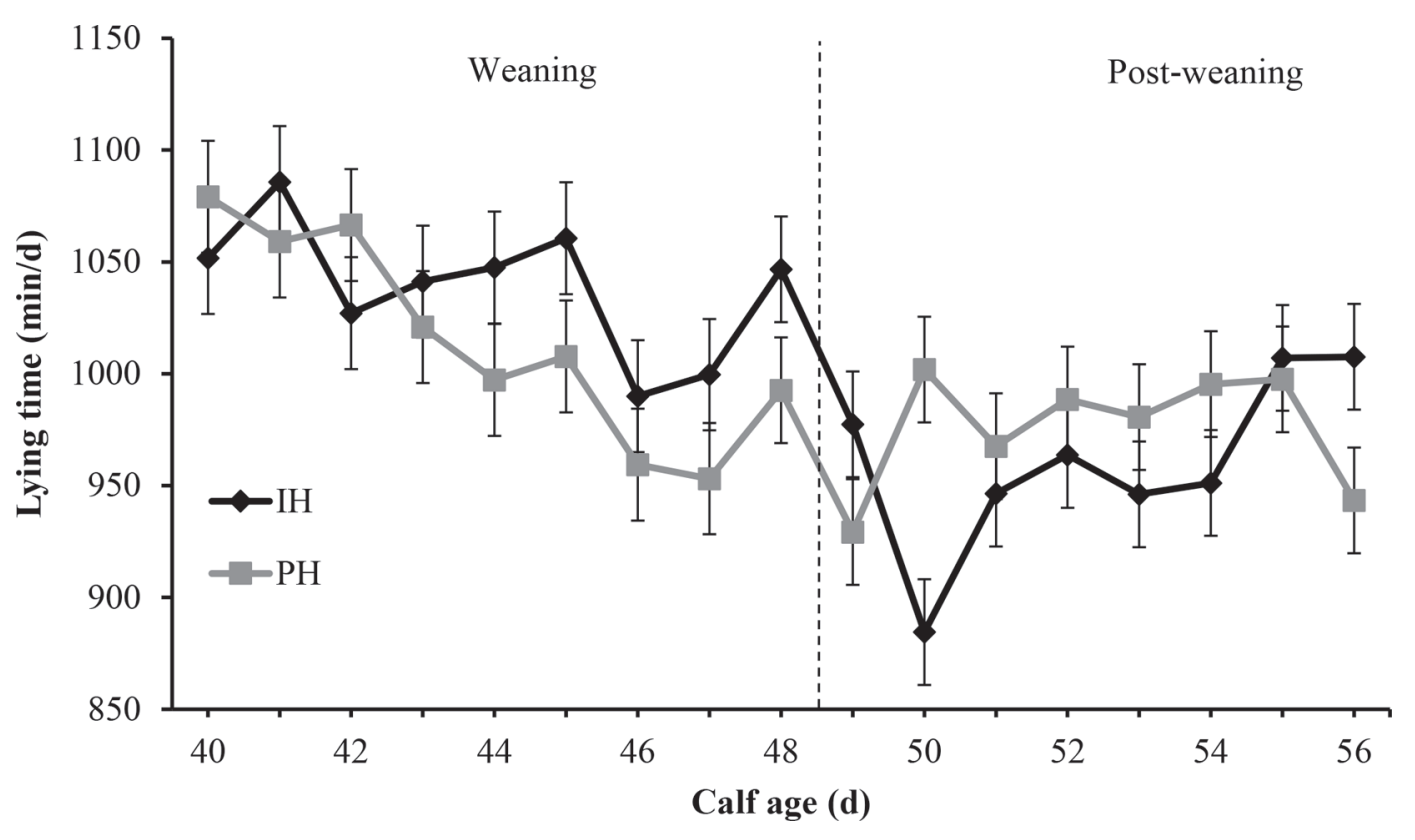

Figure 6. Mean daily lying time $( \pm \mathrm{SE})$. Values are shown separately for calves housed in individual pens for the weaning stage, then pairhoused postweaning $(\mathrm{IH})$, and calves housed in pairs for the entire trial $(\mathrm{PH})$. 


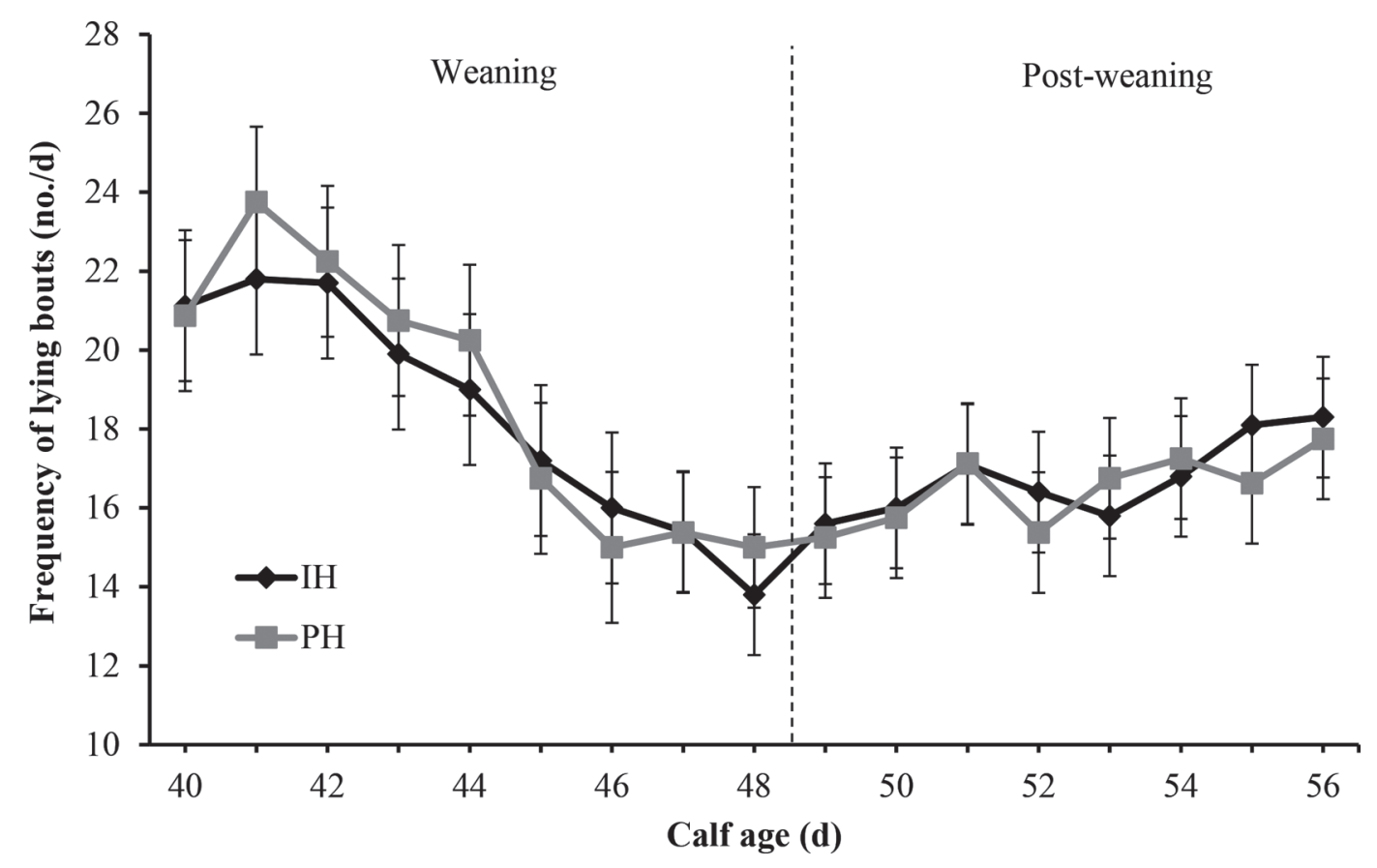

Figure 7. Mean daily lying bout frequency $( \pm \mathrm{SE})$. Values are shown separately for calves housed in individual pens for the weaning stage, then pair-housed postweaning $(\mathrm{IH})$, and calves housed in pairs for the entire trial (PH).

behavioral patterns by increasing their feeding rate to consume more DM, rather than increasing feeding time. During this period, individually housed calves tended to spend more time feeding than pair-housed calves and spent more time feeding in the early morn- ing hours than the pair-housed calves. This may reflect adjustment to the pair-housing system and the potential conflict or social facilitation of feeding with a pen-mate. Similarly, Miller-Cushon and DeVries (2016) reported a tendency for previously individually housed

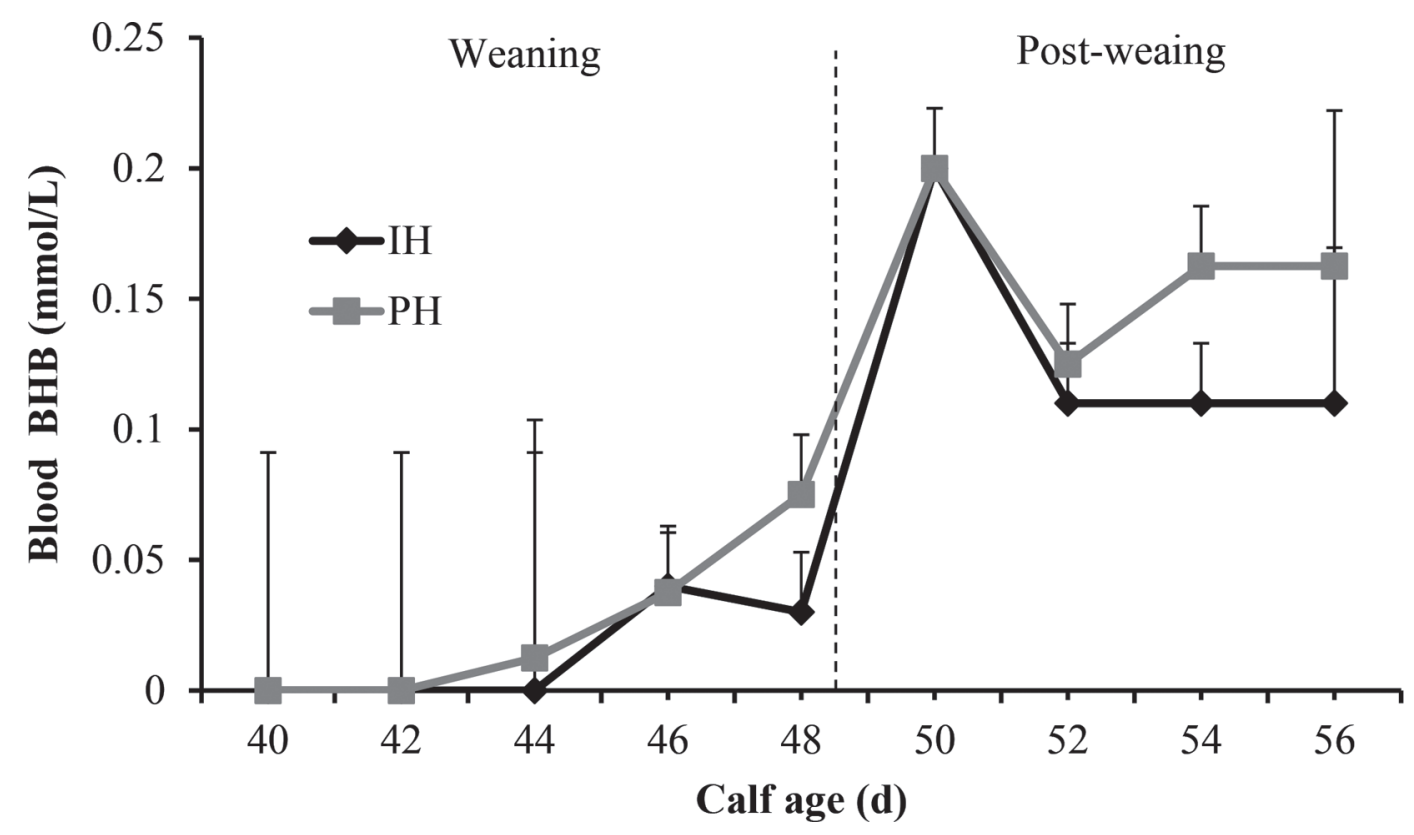

Figure 8. Mean blood BHB concentration of calves (+SE). Values are shown separately for calves housed in individual pens for the weaning stage, then pair-housed postweaning $(\mathrm{IH})$, and calves housed in pairs for the entire trial $(\mathrm{PH})$. 
calves to have less synchronized meal time, compared with calves previously raised in pairs. Although cows in competitive situations may decrease feeding synchrony and spend more time feeding at night to avoid conflict with herd-mates (Olofsson, 1999), calves in the present study each had access to a feed bucket at all times, so individually housed calves had no need to alter feeding behavior to avoid competition at feeding time. However, lack of previous experience with a social companion may influence preference for social feeding scenarios; in a preference test scenario, Miller-Cushon and DeVries (2016) reported that calves previously exposed to social housing spent more time feeding in the presence of their pen mate after weaning than calves raised individually, even when feeding places were not limited. We could also speculate that the increase in feeding time observed during the early morning hours in individually housed calves may be a result of a disruption to their feeding schedule with the introduction of a pen-mate.

Despite its importance for DMI and health, water intake is often overlooked in calf nutrition studies (Kertz et al., 1984). In a study by Kertz et al. (1984), when water availability was low, calf starter intake decreased in weaned calves. In the current study, total water intake decreased gradually over the weaning period (Figure 1 ); although free-water intake (from pails) remained constant during this time, water consumed through the diluted milk replacer decreased as calves reduced the volume of their intake. Contrary to this, de Passillé et al. (2011) reported that free-water intake increased sharply during weaning in calves fed high levels of milk and weaned by gradual reduction. This difference from the present study likely relates to the dilution weaning used in our study, which allowed for much greater water intake from milk through the weaning period. In the present study, on the first day of the postweaning period (d 49), a sharp rebound occurred in water intake, particularly for individually housed calves. This large increase in water intake corresponds to the day when dilution rose from $75 \%$ water $/ 25 \%$ milk replacer to purely water in the milk feeding apparatus. This procedure likely encouraged water intake because water was available via the milk feeding system, from which calves were accustomed to drinking milk, in addition to by bucket as usual.

Researchers have previously demonstrated that weaning by volume reduction rather than dilution encourages more solid feed intake and greater daily lying time (Nielsen et al., 2008), so it is likely that calves weaned by dilution may maintain a high liquid consumption which may offset hunger and reduce solid feed consumption. However, when housed in pairs it is difficult to successfully wean by volume reduction because more dominant calves may consume a greater portion of the reduced volume of milk than their companion. The difference in individually housed and pair-housed calves' water intake on d 49 may indicate different levels of hunger resulting from milk weaning. The individually housed calves were consuming less solid feed than pairhoused calves at the start of the postweaning phase, thus their increased water consumption from the teat could indicate a search for milk due to greater hunger, which has been shown to motivate calves to make more unrewarded visits to a feeder (De Paula Vieira et al., 2008).

To date, very little research has been conducted on lying behavior of dairy calves around the time of weaning. In the current study, pair-housed calves spent less time lying during the weaning phase. In a similar study, Chua et al. (2002) demonstrated that calves housed individually tended to spend more time lying, whereas calves in pairs spent more time standing idly and more time moving around the pen than individually housed calves. We speculate that pair-housed calves in the current study were more active than individually housed calves due to greater availability of space within their pen. Increased activity in pair-housed calves may also be due to social factors; for example, Miller-Cushon and DeVries (2016) reported that paired calves had more frequent, smaller milk meals than calves housed individually, suggesting that they may be responding to social cues. Postweaning, on d 50, individually housed calves experienced a large decrease in lying time that was not seen in the pair-housed calves; this change correlates to the day of pairing for these calves. This behavioral response is not surprising, as these calves would have experienced their first-ever direct social interactions with another calf on that day. Horvath and Miller-Cushon (2017) similarly reported an increase in standing time on the day of introduction of recently weaned calves into a group pen. von Keyserlingk et al. (2008) reported decreased lying time on the day of mixing for adult cattle, but this change did not persist to the same extent past the day of mixing, similar to the results of the current study. Thus, it appears that the individually housed calves were sufficiently adjusted to their new pen-mates $1 \mathrm{~d}$ postmixing because a treatment difference was no longer present in lying time from d 51 forward. Lying bouts decreased by day during the weaning and postweaning period, which follows the decrease in lying time and increase in feeding time seen in these phases, demonstrating that calves alter their lying behavior to accommodate changes in feeding behavior.

Previous studies of blood BHB levels around weaning have also reported an increase in blood BHB concentration with increased calf age and starter intake (Quigley 
et al., 1992; Coverdale et al., 2004; Eckert et al., 2015). The increase in blood BHB concentration that we observed over the weaning period is attributed to greater DMI of solid feed over this time period, as there would be greater production of butyrate from the fermentation of that solid feed (Coverdale et al., 2004). This process increases the development of ruminal papillae, thus calves with higher blood BHB levels are believed to have better rumen development (Khan et al., 2011; Deelen et al., 2016). Because pair-housed calves consumed more feed before the last day of weaning, we expected to see some increase in blood BHB concentration compared with individually housed calves, to indicate greater rumen development. It is likely that the high variability in BHB between treatments made it difficult to detect any treatment differences. Despite the congruent increase in blood $\mathrm{BHB}$ and starter consumption observed across all calves, the usefulness of blood BHB as a proxy for that consumption, and weaning readiness, is not clear. Deelen et al. (2016) demonstrated that a value of $0.2 \mathrm{mmol} / \mathrm{L}$ on a calf-side $\mathrm{BHB}$ meter yielded a sensitivity and specificity of 84.0 and $97.2 \%$, respectively, over a 3-d average period of starter intake ( $\geq 1,000 \mathrm{~g} / \mathrm{d})$. Suarez-Mena et al. (2017), however, reported that using such a cut-point would yield many false positives and negatives. As discussed by SuarezMena et al. (2017), it is possible that differences in calf age, time of sampling, stress, and energy balance may affect the association of blood BHB and starter intake; thus, further work is still needed to refine the usefulness of this measure to determine weaning readiness.

\section{CONCLUSIONS}

Calves altered their behavioral patterns to accommodate greater DMI to experience a successful transition from milk to solid feed at weaning. Solid feed intake, water intake, and feeding rate increased over time during the observation period, whereas lying time and lying bout frequency decreased. Blood BHB levels increased with increasing solid feed intake over the weaning period. During the weaning period, the presence of a social partner promoted greater feeding rates, which translated into greater DMI. Further, the results suggest that pair housing calves from birth may prevent disruptions to behavioral patterns that occur when calves are paired after weaning off milk.

\section{ACKNOWLEDGMENTS}

We thank the technical staff at the University of Guelph, Kemptville Campus Dairy Education and Research Centre (Kemptville, ON, Canada) for their contribution to animal care, data collection, and data processing, specifically Megan Bruce and Jakob Vogel. This project was funded through a Natural Sciences and Engineering Research Council of Canada (Ottawa, ON, Canada) Discovery Grant (T. J. DeVries), an Ontario Ministry of Agriculture, Food and Rural Affairs (Guelph, ON, Canada)/University of Guelph Production Systems research grant, and support from Nutreco Canada Inc. (Guelph, ON, Canada). This project was also supported through contributions from the Canadian Foundation for Innovation (CFI; Ottawa, ON, Canada) and the Ontario Research Fund (Toronto, ON, Canada).

\section{REFERENCES}

Appleby, M., D. Weary, and B. Chua. 2001. Performance and feeding behavior of calves on ad libitum milk from artificial teats. Appl. Anim. Behav. Sci. 74:191-201.

Baldwin, R. L., K. R. McLeod, J. L. Klotz, and R. N. Heitmann. 2004. Rumen development, intestinal growth and hepatic metabolism in the pre- and postweaning ruminant. J. Dairy Sci. 87:E55-E65.

Bolt, S. L., N. K. Boyland, D. T. Mlynski, R. James, and D. P. Croft. 2017. Pair housing of dairy calves and age at pairing: Effects on weaning stress, health, production and social networks. PLoS One 12:e0166926

Bonk, S., O. Burfeind, V. S. Suthar, and W. Heuwieser. 2013. Technical note: Evaluation of data loggers for measuring lying behavior in dairy calves. J. Dairy Sci. 96:3265-3271.

Castells, L., A. Bach, G. Araujo, C. Montoro, and M. Terré. 2012. Effect of different forage sources on performance and feeding behavior of Holstein calves. J. Dairy Sci. 95:286-293.

CCAC (Canadian Council on Animal Care). 2009. CCAC Guidelines on the Care and Use of Farm Animals in Research, Teaching and Testing. Canadian Council on Animal Care. Ottawa, ON, Canada.

Chua, B., E. Coenen, J. van Delen, and D. M. Weary. 2002. Effects of pair versus individual housing on the behavior and performance of dairy calves. J. Dairy Sci. 85:360-364.

Costa, J. H. C., R. R. Daros, M. A. G. von Keyserlingk, and D. M. Weary. 2014. Complex social housing reduces food neophobia in calves. J. Dairy Sci. 97:7804-7810.

Costa, J. H. C., R. K. Meagher, M. A. G. von Keyserlingk, and D. M. Weary. 2015. Early pair housing increases solid feed intake and weight gains in dairy calves. J. Dairy Sci. 98:6381-6386.

Costa, J. H. C., M. A. G. von Keyserlingk, and D. M. Weary. 2016. Invited review: Effects of group housing of dairy calves on behavior, cognition, performance, and health. J. Dairy Sci. 99:2453-2467.

Coverdale, J. A., H. D. Tyler, J. D. Quigley, and J. A. Brumm. 2004. Effect of various levels of forage and form of diet on rumen development and growth in calves. J. Dairy Sci. 87:2554-2562.

de Passillé, A. M., T. F. Borderas, and J. Rushen. 2011. Weaning age of calves fed a high milk allowance by automated feeders: Effects on feed, water, and energy intake, behavioral signs of hunger, and weight gains. J. Dairy Sci. 94:1401-1408.

De Paula Vieira, A., A. M. de Passillé, and D. M. Weary. 2012. Effects of the early social environment on behavioral responses of dairy calves to novel events. J. Dairy Sci. 95:5149-5155.

De Paula Vieira, A., V. Guesdon, A. M. de Passillé, M. A. G. von Keyserlingk, and D. M. Weary. 2008. Behavioral indicators of hunger in dairy calves. Appl. Anim. Behav. Sci. 109:180-189.

De Paula Vieira, A., M. A. G. von Keyserlingk, and D. M. Weary. 2010. Effects of pair versus single housing on performance and behavior of dairy calves before and after weaning from milk. J. Dairy Sci. 93:3079-3085.

Deelen, S. M., K. E. Leslie, M. A. Steele, E. Eckert, H. E. Brown, and T. J. DeVries. 2016. Validation for a calf-side $\beta$-hydroxybutyrate test and its utility for estimation of starter intake in dairy calves around weaning. J. Dairy Sci. 99:7624-7633. 
Duve, L. R., D. M. Weary, U. Halekoh, and M. B. Jensen. 2012. The effects of social contact and milk allowance on responses to handling, play, and social behavior in young dairy calves. J. Dairy Sci. 95:6571-6581.

Eckert, E. C., H. E. Brown, K. E. Leslie, T. J. DeVries, and M. A. Steele. 2015. Weaning age impacts growth, feed intake, gastrointestinal development and behavior of Holstein calves fed an elevated plane of nutrition during the pre-weaning stage. J. Dairy Sci. 98:6315-6326.

Gaillard, C., R. K. Meagher, M. A. G. von Keyserlingk, and D. M. Weary. 2014. Social housing improves dairy calves' performance in two cognitive tests. PLoS One 9:e90205.

Gelsinger, S. L., A. J. Heinrichs, and C. M. Jones. 2016. A metaanalysis of the effects of preweaned calf nutrition and growth on first-lactation performance. J. Dairy Sci. 99:6206-6214.

Hintze, J. 2008. PASS 2008. NCSS, LLC, Kaysville, UT.

Horvath, K., and E. K. Miller-Cushon. 2017. Characterizing activity at social grouping in weaned dairy calves. J. Dairy Sci. 100(E Suppl. 2.):228

Iwersen, M., U. Falkenberg, R. Voigtsberger, D. Forderung, and W. Heuwieser. 2009. Evaluation of an electronic cowside test to detect subclinical ketosis in dairy cows. J. Dairy Sci. 92:2618-2624.

Jasper, J., and D. M. Weary. 2002. Effects of ad libitum milk intake on dairy calves. J. Dairy Sci. 85:3054-3058.

Jensen, M. B., L. R. Duve, and D. M. Weary. 2015. Pair housing and enhanced milk allowance increase play behavior and improve performance in dairy calves. J. Dairy Sci. 98:2568-2575.

Kertz, A. F., L. F. Reutzel, and J. H. Mahoney. 1984. Ad libitum water intake by neonatal calves and its relationship to calf starter intake, weight gain, feces score, and season. J. Dairy Sci. 67:2964-2969.

Khan, M. A., A. Bach, D. M. Weary, and M. A. G. von Keyserlingk. 2016. Invited review: Transitioning from milk to solid feed in dairy heifers. J. Dairy Sci. 99:885-902.

Khan, M. A., H. J. Lee, W. S. Lee, H. S. Kim, S. B. Kim, K. S. Ki, J. K. Ha, H. G. Lee, and Y. J. Choi. 2007. Pre- and postweaning performance of Holstein female calves fed milk through step-down and conventional methods. J. Dairy Sci. 90:876-885.

Khan, M. A., D. M. Weary, and M. A. G. von Keyserlingk. 2011. Hay intake improves performance and rumen development of calves fed higher quantities of milk. J. Dairy Sci. 94:3547-3553.

Meagher, R. K., R. R. Daros, J. H. C. Costa, M. A. G. von Keyserlingk, M. Hotzel, and D. M. Weary. 2015. Individual housing impairs reversal learning and increases fear of novel objects in dairy calves. PLoS One 10:e0132828.

Miller-Cushon, E. K., R. Bergeron, K. E. Leslie, and T. J. DeVries. 2013a. Effect of milk feeding level on development of feeding behavior in dairy calves. J. Dairy Sci. 96:551-564.

Miller-Cushon, E. K., R. Bergeron, K. E. Leslie, G. J. Mason, and T. J. DeVries. 2013b. Effect of early exposure to different feed presentations on feed sorting of dairy calves. J. Dairy Sci. 96:4624-4633.

Miller-Cushon, E. K., R. Bergeron, K. E. Leslie, G. J. Mason, and T. J. DeVries. 2013c. Effect of feed presentation on feeding patterns of dairy calves. J. Dairy Sci. 96:7260-7268.

Miller-Cushon, E. K. R. Bergeron, K. E. Leslie, G. J. Mason, and T. J. DeVries. 2014. Competition during the milk-feeding stage influences the development of feeding behavior of pair-housed calves. J. Dairy Sci. 97:6450-6462.

Miller-Cushon, E. K., and T. J. DeVries. 2011. Technical Note: Validation of methodology for characterization of feeding behavior in dairy calves. J. Dairy Sci. 94:6103-6110.
Miller-Cushon, E. K., and T. J. DeVries. 2016. Effect of social housing on the development of feeding behavior and social feeding preferences of dairy calves. J. Dairy Sci. 99:1406-1417.

Morris, T. R. 1999. Experimental Design and Analysis in Animal Sciences. CABI Publishing, New York, NY.

Nielsen, P. P., M. B. Jensen, and L. Lidfors. 2008. The effects of teat bar design and weaning method on behavior, intake, and gain of dairy calves. J. Dairy Sci. 91:2423-2432.

Olofsson, J. 1999. Competition for total mixed diets fed for ad libitum intake using one or four cows per feeding station. J. Dairy Sci 82:69-79.

Overvest, M. A., R. Bergeron, D. B. Haley, and T. J. DeVries. 2016. Effect of feed type and method of presentation on feeding behavior, intake, and growth of dairy calves fed a high level of milk. J. Dairy Sci. 99:317-327.

Quigley, J. D., L. A. Caldwell, O. D. Sinks, and R. N. Heitmann. 1991. Changes in blood glucose, nonesterified fatty acids, and ketones in response to weaning and feed intake in young calves. J. Dairy Sci. 74:250-257.

Quigley, J. D. T. M. Steen, and S. I. Boehms. 1992. Postprandial changes of selected blood and ruminal metabolites in ruminating calves fed diets with or without hay. J. Dairy Sci. 75:228-235.

Rosenberger, K., J. H. C. Costa, H. W. Neave, M. A. G. von Keyserlingk, and D. M. Weary. 2017. The effect of milk allowance on behavior and weight gains in dairy calves. J. Dairy Sci. 100:504-512.

Soberon, F., E. Raffrenato, R. W. Everett, and M. E. Van Amburgh 2012. Preweaning milk replacer intake and effects on long-term productivity of dairy calves. J. Dairy Sci. 95:783-793.

Soberon, F., and M. E. Van Amburgh. 2013. Lactation biology symposium: The effect of nutrient intake from milk or milk replacer of preweaned dairy calves on lactation milk yield as adults: A metaanalysis of current data. J. Anim. Sci. 91:706-712.

Stanton, A. L., D. F. Kelton, S. J. Leblanc, J. Wormuth, L. K. Fox, and K. E. Leslie. 2013. Effects of tulathromycin on incidence of various diseases and growth of young heifers. J. Am. Vet. Med. Assoc. 243:267-276.

Suarez-Mena, F. X., W. Hu, T. S. Dennis, T. M. Hill, and R. L. Schlotterbeck. 2017. $\beta$-hydroxybutyrate (BHB) and glucose concentrations in the blood of dairy calves as influenced by age, vaccination stress, weaning, and starter intake including evaluation of BHB and glucose markers of starter intake. J. Dairy Sci. 100:2614-2624.

Swanson, E. W., and J. D. Harris. 1958. Development of rumination in the young calf. J. Dairy Sci. 41:1768-1776.

Sweeney, B. C., J. Rushen, D. M. Weary, and A. M. de Passillé. 2010. Duration of weaning, starter intake, and weight gain of dairy calves fed large amounts of milk. J. Dairy Sci. 93:148-152.

Terré, M., M. Devant, and A. Bach. 2007. Effect of level of milk replacer fed to Holstein calves on performance during the preweaning period and starter digestibility at weaning. Livest. Sci. 110:82-88

UBC AWP. 2013. UBC Animal Welfare Program: SOP - HOBO Dat Loggers. pp. 1-23. University of British Columbia, Vancouver, Canada.

von Keyserlingk, M. A. G., D. Olenick, and D. M. Weary. 2008. Acute behavioral effects of regrouping dairy cows. J. Dairy Sci. 91:10111016 